\title{
STRUCTURES AND NETWORKS IN THE BRITISH HEALTH SERVICE REFORMS
}

Maureen Mackintosh

The dominant international agenda for public sector reform has moved on in the last few years. From privatization - substituting private for state production - reformers have turned to efforts to reform the internal working relations within state production. We could call this new model the 'competitive state': a state which, as far as possible, functions like a competitive market.

As with privatization, so in its new public sector reforms the British government seems to be developing a model which it might wish to export. While blueprints for fully fledged 'internal markets' do not seem to be currently widespread among development agencies' policy reviews, elements of the model are appearing in World Bank and other proposals for public service reform. ${ }^{1}$

This seems a good moment, therefore, to reflect upon one of the most sweeping of the British public service reforms - the creation of a so-called internal market within the National Health Service - in the light of its possible role in British invisible exports.

The argument of this article is as follows. The intellectual roots of these 'competitive state' reforms lie in a strictly individualist and materialist model of economic behaviour. The reforms themselves have therefore been carried through on the implicit assumption - which also apparently underlies early privatization efforts in countries with poorly developed markets $^{2}$ - that opportunities only have to be provided, for competitive markets to emerge. It follows that an enforced separation between 'purchasers' and 'providers' within a public service, backed up by cost accounting and formal contracting for services, will create a satisfactory 'internal' market.

There are, however, a number of divergent views among commentators and policy makers about what constitutes appropriate competitive behaviour on such a curious market. In the British health service reforms, Department of Health guidance seems to be thin and rather contradictory on this issue. In practice therefore, health service managers are bound to build their responses to these new 'market' pressures and opportunities upon their existing working norms, practices, ethics and power relations. As a result, a very diverse set of practices appear to be emerging within the rather 'empty shell' of the contracting process.

Some of these early developments cast doubt upon both the logic of the reforms and their practical effect. They should give pause for thought about the export of such a model. They also suggest some alternative lines of thought: professional and ethical principles, and outward accountability are relevant variables in both North and South, in constructing alternatives to bureaucratic hierarchy.

\section{INDIVIDUALIST ASSUMPTIONS}

The British public service reforms are rooted intellectually in the increasingly influential ideas of the 'public choice' school of economists. This school of thought has developed one central idea about the behaviour of politicians and state employees into an intellectual and political programme. As the school's founder, James Buchanan puts it, ' . . . these people act no differently from other persons the economist studies'; that is, their behaviour can be modelled as seeking to follow their own self-interest, narrowly defined in material terms. 'Recognition of this simple point', Buchanan continues, is a necessary part of political analysis (Buchanan 1986:24, 26).

The word 'recognition' is interesting here: like many people working within this school of thought, Buchanan regards this point as self evident once stated. Although this premise has been attacked as both logically incomplete and empirically dubious, ${ }^{3}$ nevertheless a substantial body of theory and policy proposals has been built upon it which has abolished some traditional distinctions. One such is the distinction between 'social policy' and 'economic policy'; another, the distinction between a realm of economic decision making where policy makers pursue some view of the public interest (e.g. public services) and another arena where there is legitimate pursuit of private interests ('the market').

Some of these attacks on conventional wisdom have had a beneficial and head-clearing effect. To exclude public services such as health from the realm of economic policy was always dubious, and the assumption that public servants maximized a politically-

\footnotetext{
1 Mackintosh (1992) has a more detailed discussion of this point.

2 Crow and Harriss (1992) make this argument for agricultural market
}

deregulation in a number of African and Asian countries.

3 For example, Sen (1976); Hodgson (1988). 
defined social welfare function was always a curious one. We need, however, to take a hard look at what is being offered in its place.

The public choice assumption of materialistic individualism generates an attack on hierarchical organization of public services. The public choice critics suggest that public service providers ('bureaux') tend to develop their own self-expansionary goals: to work for themselves, not for the public. Most important, the theorists attribute this tendency experienced at some point by most public service users - not to improper behaviour on the part of public employees (since everyone will, properly, pursue their own interests) but to organizational failure.

Public services develop self-serving goals, the critics argue, because they are monopolies; they monopolize provision and information and face powerless consumers. The consumers are powerless because they have no purchasing power, hence cannot exercise choice.

The solutions follow immediately. If one assumes that behaviour within the state resembles that within the market, then individualistic market models generate proposed solutions. If monopoly is the problem, competition is the answer. If lack of purchasing power is a problem, stronger purchasers are the answer. In other words, if services cannot be wholly privatized because of dependence on tax finance, then the next best approach is for the state to stimulate a competitive market. Bureaucratic hierarchy is to be replaced with competing market institutions within the state as well as across its boundaries.

\section{THE REFORMED STRUCTURE}

The public choice school has more than a whiff of specifically United States individualism about it, and the British health service reforms were built in part on proposals by Alain Enthoven, an academic with extensive US experience. The National Health Service (NHS) in Britain has long been unusual in industrialized countries for its fusion of public (tax) finance and provision into a single large organization. At the time of the British Government's White Paper Working for Patients (HMSO 1989) which set out the current reform agenda, the NHS was already undergoing a major change in management structure, moving away from 'consensus' management among professional groups to a line management structure with a general manager in charge of each unit and institution (Strong and Robinson 1990). But that major set of changes had left the integration of finance and provision untouched.

The wave of reform which began in $1989 / 90$ set out to break that relation, separating the 'purchasers', who finance provision, from the 'providers', that is hospitals, ambulance services, clinics and community services. The aim, consistent with the school of thought outlined above, was to break up monopoly provision, allowing purchasers to shop around, and forcing providers to compete for custom. This internal market' was intended, in Enthoven's argument, to retain the strengths of the NHS, which he identified as including, 'universal coverage, effective cost containment, regional concentration of costly specialized services and a strong primary care system'. At the same time it was intended to overcome the weakness, identified as 'rigidity, overcentralization and a complete lack of incentive for innovation and improvement in efficiency' (Enthoven 1991:61).

There is one particular peculiarity, however, about this proposed market within a huge public organization: the 'purchasers' are not the patients (nor, as in most industrialized countries, insurance companies). Instead the purchasers are mainly the District Health Authorities, the organizations which previously managed the hospitals and other services. These now have a tax-financed budget, which will eventually be based on population in their areas (weighted somewhat by need), to purchase services on their behalf. In addition, a relatively small amount of purchasing is done by general practitioners (GPs), that is, by the primary doctors in the British health system who refer on to other services, and some of whom (some larger practices) have budgets to purchase services from hospitals. In the future, this role of purchasing by doctors is likely to expand, for example into purchasing community nursing services.

The reason for this peculiarity is the uncertainty associated with ill health. In education, for example, the public choice theorists, typically, propose that people with school age children be given 'vouchers' to 'purchase' a school place. But ill health is unpredictable, hence the need for large purchasing budgets to spread risk across large populations. The result has been called a 'quasi-market', in a borrowing from the literature on large private firms which establish profit centres and internal trading (Le Grand 1991).

The effect then has been to divide the previous pyramidal hierarchy horizontally, inserting a, supposedly, competitive market. The provider institutions are being given various degrees of autonomy from their previous bosses - the health authorities. The greatest autonomy is represented by the NHS Trusts, that is, non-profit organizations which own their own assets and have considerable management freedom. But other units are also intended to manage their own organization and contracting strategy. 


\section{Inserting the Internal Market}

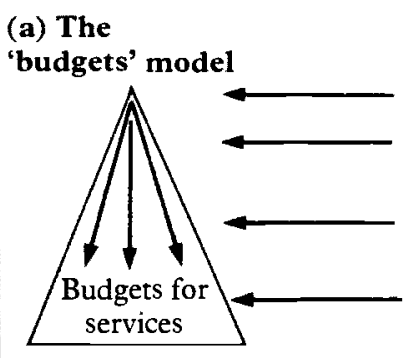

Department of Health

Regional Health

Authorities

District Health

Authorities

Health care

producers

(b) The

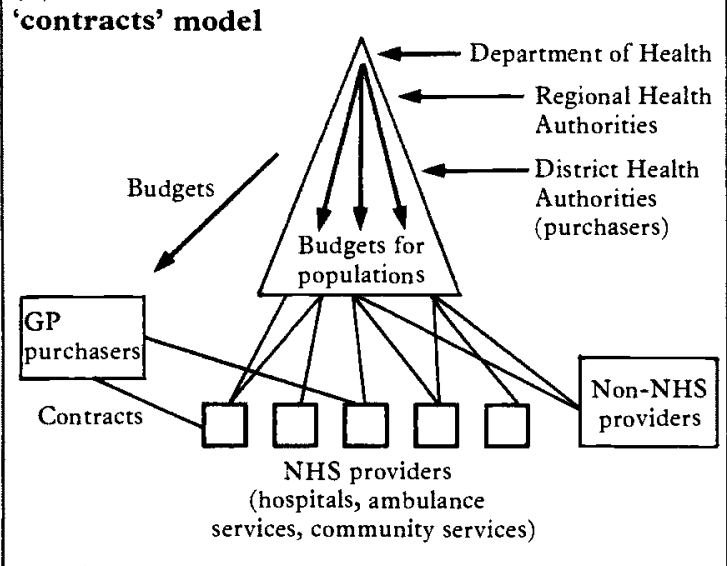

As the reforms develop, purchasers may look, not only to existing providers but also to new for-profit or nonprofit providers of the services they wish to purchase.

\section{COMPETITION OR CO-OPERATION: DETERMINING CONTRACTING BEHAVIOUR}

Once the purchaser/provider 'split' has been established, how should the two sides behave in establishing contracts between them? This is no idle question. The point of the reforms, as already argued, was to change behaviour. The contracting structure, it was hoped, would increase the incentives for 'providers' (that is, the producers of health care) to use resources efficiently (since 'better' providers would see resources expand), while increasing incentives for 'purchasers' to respond to the needs of their population. So what are the incentives in the new system, and how are people likely to react to them?

4 There are three types of contract. 'Block' contracts are essentially input contracts, and hence resemble budgets: a sum of money for providing a given service. 'Cost and volume' contracts are through put contracts: a sum of money for a given number of patients
A number of possible problems of perverse incentives have been identified in debate on the reforms. A good example concerns the maintenance of quality: important, since the reforms were explicitly intended to promote good quality and not simply low cost health care (HMSO 1989:5).

The quality problem arises as follows. Let us suppose that the public choice assumptions hold: people generally pursue their own material interests. Consider first the purchasers. These are supposed to be public spirited: to serve their public. But they are towards the top of the bureaucracy, a long way from the patients, and are appointed, funded, and monitored from above. Of course, purchasers can choose to respond to their public, and may have to account for having done so, but they are not accountable downwards. They will therefore, on this behavioural theory, be highly swayed by the priorities of the Department of Health, their paymasters. And the Department of Health may well be in practice very focused on access to, and throughput through the system (for example, centrally concerned with waiting lists).

Now consider the providers; hospitals for example. They are closer to the patient, hence under some pressure from them. But patients often find it hard to judge the quality of their treatment, and exercise relatively little leverage (since they are not paying at the time for treatment). Payment to providers under the government's preferred cost-and-volume contracts ${ }^{4}$ tends to increase with numbers treated, at least after a certain threshold. And providers are under competitive pressure on costs, given limited tax finance.

The result, if we accept the behavioural assumptions of public choice, is that there will be a tendency to collusion among purchasers and providers to cut quality in the interests of reducing cost. This, furthermore, was exactly the behaviour found in the 'Rubber Windmill' simulation of the reforms at the time of the White Paper. In the logic of the system, the report on the simulation pointed out, 'providers are to an extent freed from direct responsibility for health outcomes'. With purchasers being judged from above by their ability to drive down costs, ' $\ldots$ there exist circumstances in which both purchasers and providers may walk away from quality issues'. (East Anglian Regional Health Authority 1990:11).

The widespread fear within the NHS that the reforms may reduce quality therefore has a basis in the logic of incentives within the system. If people behave 'as if' they were materialistic market participants quality may

treated, with additional cash for additional throughput over a specified threshold. Case by case contracts price each 'episode' of provision, and are the most costly in administrative time. 
deteriorate. Commentary on this problem has taken two alternative lines. One, fairly typical of orthodox economics, is to point out that the market cannot work 'properly' unless people do behave materialistically, and play out market-like roles.

Fergusson and Posnett (1990), for example, treat as problems all the ways in which this market differs from a highly competitive private trading system. Other commentators identify, 'a reluctance at unit level to let go of responsibility for the community. This is entirely laudable and understandable, but may get in the way of units acting as true providers'. (Brooks and Lewe n.d.). And others add, 'The main priority in $1991 / 92$ is to move from contracting to real purchasing'. (Ham and Matthews 1991). This seems to mean shopping around, and moving away from a budget-based mentality of working with specific providers.

Other observers and, particularly, participants in the reforms are more cautious. Private health markets, it is well known, tend to be inefficient and inequitable and to need heavy regulation. One central reason for this is that information in health care is largely monopolized by providers: all health care systems, whatever their institutional structure, tend to be provider-led. As a result there are two central ingredients for regulation; information for outside regulators (necessarily limited, since outcomes of health care are very hard to measure) and professional norms and ethics. And the essence of professional ethics is that the provider should seek to provide the best treatment for the patient. As just noted, this idea runs against the strict, 'public choice' interpretation of the reform process logic.

On this second interpretation, which recognizes the central role of ethics, the health service reforms cannot 'work' unless people do not behave as pure market participants. On the contrary, this view suggests, the quality of provision will deteriorate unless providers continue to take responsibility for need and response to need, and providers allow them to do so.

The Department of Health appears, at least partially, to hold this second viewpoint. Their advice to providers and purchasers on their proper behaviour under contracting is thin, and in some ways contradictory, but it certainly recognizes the problem just outlined.

The contracting process, says Department of Health guidance, is 'not . . . a legalistic or adversarial process' (HMSO 1990:1). Furthermore, 'specifications should be shared, being constructed in collaboration with providers, and their clinical staff, and also with GPs, FHSAs [Family Health Service Authorities, which fund general practitioners] and local authorities to establish common views'. (NHS Management
Executive 1991, quoting an earlier paper from the same source; emphasis in original.) In case the message has been missed, the paper goes on: 'The purchaser/prorider split should not disrupt good local relationships' and 'existing informal networks should be encouraged' (ibid pp 6-7, emphasis in original). The guidance adds that ensuring quality should rest on provider shoulders: the purchaser's role is to ensure that the provider has the capacity and procedures to ensure quality. Finally, contracts do not have the force of law: there is no place for litigation, with arbitration the only recourse.

So far, so co-operative. However, when we turn guidance on costing and pricing behaviour, adversarial relations between purchaser and provider suddenly reemerge. The pricing rules are sketchy, being limited to the state ment that prices should be based on 'full' costs without 'planned cross-subsidization' (HMSO 1990:18, inverted commas around 'full' in the original). However, health authorities will be 'expected to use the contractual process to achieve value for money and to extract efficiency gains from providers'. 'The clear intention is that DHAs [District Health Authorities] secure CIs [cost improvements] through the contract prices they pay.' (ibid: 17).

In other words, providers and purchasers, when they are trying to determine appropriate behaviour to structure the market they are creating, find themselves being urged both to co-operate and to compete. How, in these circumstances, are they likely to behave in practice?

\section{REFORM IN PRACTICE: FILLING AN EMPTY SHELL}

How contracting parties - purchasers and providers - behave will determine the implications for patients of the reform in practice. Markets, both 'internal' and otherwise, are not natural institutions which emerge in much the same form wherever there is freedom to trade. Instead, markets are very varied social institutions which are strongly structured by participant behaviour.5 And in many, perhaps all markets, participants depend heavily on being able to predict such behaviour on most occasions. In addition to short term material incentives, markets are found to be influenced heavily by social norms, and ethical relations such as trust and professionalism. Market contracts are rarely 'complete': instead of specifying a response for every contingency, they rely heavily on shared definitions and implicit expectations.

Health care contracts in the NHS internal market are certainly incomplete in this sense, as the Department of Health guidance cited acknowledges. Hence, health

\footnotetext{
5 Auerbach (1988) argues this point for a private market.
} 
service managers need quickly to fill this 'empty shell' of a contracting system with mutually understood and accepted patterns of behaviour. They are almost bound to do this largely on the basis of existing social norms and practices, and indeed that is what the Department of Health seems to expect in its references to 'networks' just cited. Where outsiders come into the process, they will bring new norms, for example from the private business world, but they will also have to relate those norms to the environment which they find.

But norms and networks are quite diverse in the NHS, an organization which, while large, has never been homogeneous. To illustrate this diversity, here are two ideal-typical examples of how that diversity may develop. The examples are both cases of 'provider' behaviour, and are 'constructed' cases drawn from a range of information and discussion. They therefore refer to no specific institution or unit within the NHS, but are not unrealistic, and are designed to demonstrate the differing pressures and responses which seem to be emerging in the early stages of reform.

The first case is that of a tertiary referral unit within a large teaching hospital: that is, a unit which typically takes difficult cases referred on by other hospitals. Many such units have hired a business manager, and are developing a business plan. On what will the business manager, unit general manager, and associated consultants base their contracting strategy?

This type of third tier unit has some characteristic features: for example, relatively high costs per patient, because of the complexity of the procedures and also possibly because of geographical location; part time consultants, some of them eminent; and a referral pattern which is geographically widespread, though possibly quite regionally focused. As result of these characteristics the finances of such units are generally threatened by the reforms, since the purchasers will tend to seek lower cost (and possibly lower quality) solutions once they see the prices the unit has to charge.

What is the likely response of the managers? Such units tend to seek to compete aggressively on quality since they cannot hope to compete on cost. They are also seeking to cut costs, for example by subcontracting simpler elements of procedures, and patients' recuperation, to cheaper locations. They are likely to price their service per patient, on an average cost or even case by case basis (which is costly in accountants' time). This is a classic marketing strategy focused on discerning and building a quality-based 'niche'. So far, this appears to be 'market-like' behaviour.

But what does 'marketing' mean here? Who are the purchasers? They are primarily the District Health Authorities: these are not procedures which fall within general practitioners' (GPs') budgets. In another sense, the purchasers are the doctors who seek referrals to the unit, and hence propose a contract to the health authority. The other arm of the marketing strategy therefore must be networking: making sure that the purchasers are impressed with the service, backing up marketing brochures with pressure through personal contacts with decision makers. This means building, in other words, on élite networks to try to maintain high cost specialist provision.

This is one type of strategy. It corresponds rather closely to many of the images promoted of the health service reforms. It is a relatively recognizable market or marketing-type strategy and incorporates both quality criteria and efforts at cost cutting. It also, however, depends for its success on the strength of medical networks in trying to persuade Health Authorities to spend the money on expensive procedures.

A second and contrasting example is that of a community unit, such as a group of local health centres providing community nursing, health promotion and health visiting. Such a unit typically has a heavy workload, coping with referrals from a variety of sources (social workers, GPs, hospitals), but working in a single locality. They provide a wide variety of nursing care to an increasingly dependent group of people, as the population ages and hospitals send people home earlier. The nursing is combined with social care (a link to the outside world, conversation), and the nurses network locally with many other agencies. They face current pressures to take on more people for the same cost, by using increasing numbers of less-skilled personnel backing up each trained district nurse. They also face some proposals to fragment the service, with different providers supplying nursing to different client groups (Taylor 1991:36).

A comprehensible response from this group of managers is to resist moves towards marketing services and towards more competitive behaviour. They start from very different social norms and working styles from those in the first example. In addition to providing case by case care, such a unit has often come to see its role as managing and prioritizing response to need in a locality, based on its own work and networking. Furthermore, some purchasers share this vision. Cooperation between purchasers and providers may be facilitated when purchasing advisers come from the same professional background as providers (something which is less likely in the first case).

Hence the networking here may seek to maintain an integrated generic nursing service in a locality, leaving the providers with considerable responsibility for identifying and prioritizing need in local hands. Both purchasers and providers often prefer 'block' contracts, 
which provide a specific sum (previously called a budget) for a broad local service. There may be considerable mutual resistance to monitoring criteria which focus on 'throughout' measures, and to the setting of detailed priorities at purchaser level. Both 'sides' may resist the introduction of competing providers at local level, not only (or even mainly) because of a fear of competition, but because of a commitment to concepts of local networking and co-ordination.

This is a different response to contracting. Instead of identifying a closely defined niche, it tries to retain a broad remit. And the networks it draws upon are socially very different. However, the responses in the two cases do also have common features. They both seek to keep substantial control over the definition of need and the quality and delivery of the service in provider hands. And they both build on existing working practices to respond to changing pressures.

\section{LESSONS FOR REFORMERS}

There are, I suggest, some general lessons to be drawn from this brief excursion into the logic of the reforms and the two examples.

The first is that there is a logical flaw at the heart of these reforms. The structure of the reforms does not in fact assume that everyone is materialistically inclined: it assumes that only the people at the top should be relied upon to serve the public interest. This is typical of most of the British public service reforms, which are based on a model of a public-spirited set of policy makers at the top and commercial-style management lower down. ${ }^{6}$

The odd thing about this approach is that it runs against what most people feel is realistic. In discussing the 'public choice' ideas, people very often find them entirely plausible for top civil servants, but baulk when they are applied to nursing staff. In taking the opposite line, reformers open themselves to charges of illogicality. If people, including civil servants and politicians, are assumed to be self-seeking, then those with the least public pressure and visibility are likely on these assumptions to be the least responsive, and those under daily pressure from the public will be better. To make the opposite assumption is perverse.

The second lesson follows from the discussion of behaviour and of the examples. In service industries, public or private, the crucial determinant of what is delivered is the relation between individual providers

6 There is an exception to this generalization, which is the structure of the reform of 'community care' (social care for people within their own homes). This reform puts purchasing in the hands of individual care managers with small budgets; it generates a different series of (or groups of providers) and customers or clients. Contracts can neither capture nor enforce this, and the 'purchasers' in a quasi-market do not experience it. Its quality is determined by the motivation, skills and backup for providers. If providers do not take responsibility for quality, it will not improve.

One central problem with the reforms, then, is their impact on this mix of motivation, skills and backup: in other words on the professional behaviour of providers. Criticism of self-defensive professional behaviour has been widespread and well-taken in recent years. But there are also good sides to professionalism: for example, overt standards, and a sense of 'owning' the output (rather than simply doing a job) which produces motivation and effectiveness (including hard work). If a mixture of cost cutting and a perceived assumption by purchasers of unprofessional (materialistic) behaviour undermines morale, then it is possible that the service might lose a lot more (in staff demotivation and lower quality) than it gained in lower costs.

The discussion above suggested why such demotivation might be disastrous. It was argued that most participants in the health service reforms see the importance of continuing provider responsibility for quality, despite the conflicts between this and how the reforms are 'supposed' to work. If providers were to reduce their commitment to their communities, it is likely that the reforms would deliver lower quality provision. Interestingly, some private sector commentators on the reforms have worried aloud about this problem, ${ }^{7}$ having a less simplistic image of private sector markets and management than some public sector market converts. It seems that it might be better, and this is the third point, to try to strengthen the accountability of providers to their clients.

How that could be done would require another article. The variety of ideas is great. Some commentators suggest strengthening the role of GP purchasers, on the grounds that they are closer to their patients, and under more effective pressure from them, than are the Health Authorities. One problem with this is that the smaller and closer to patients purchasers become, the less purchasing power they have and the more difficult it becomes to spread risk. Alternatively, in the mental health and community care worlds, there are some different and creative ideas about strengthening user influence in contracting. Hawker and Ritchie (n.d.), for example, examine a range of approaches including user-managed schemes and what they call 'collusion of interests' management, where a group of users, advocates and practitioners 'collude' around a common

issues and problems, not addressed here

7 For example, Chambers (1989) comments that private sector organizations, "have been transformed by focusing on the morale of the providers rather than by concentrating on measuring outcomes'. 
set of values, and seek (contractual) resources to pursue their approach. The diversity of health service worlds, sketched briefly above, demand diverse and appropriate approaches. The central point here is that the structure of NHS reform initially directed attention away from the question of user involvement in contracting (apart from consultation by purchasers); however the issues discussed in this paper are conspiring to return the user-provider link to the agenda.

The fourth lesson follows from the above: simplistic models of efficient markets are dangerous if taken literally. Markets in the real world are complicated social institutions. Where a market has not existed before, its development will be influenced by existing economic and social relationships as well as by new incentives. How people behave as market participants is crucial to outcomes, and doubly so in professional service industries. And behaviour and response to an apparently identical (contracting) structure may be very different in different parts of the structure.

Reformers therefore need to take questions of behaviour and motivation seriously. Introducing a 'market' does not absolve policymakers (purchasers) from thinking about the organization of the provider side of the fence. If the implications of the reforms confuse or undermine providers, provision may deteriorate despite the apparent improvement in material incentives (such as more clients implying more cash). There are some clear efforts within the health service to avoid this scenario at present, and the reforms are too recent for long term effects to be clearly visible.

All of these lessons come back, finally, to the importance of the assumptions reformers make about other people's behaviour. Far from being a 'simple' point, the assumption of self-seeking behaviour has problematic consequences. One could state the issue most starkly as follows. Empirically, at any given place and time, public service workers' and managers' motivations may be materialistic or public spirited - or rather, a weighted mixture of the two. But we know that for public services to run well, there is simply no substitute for ethical and professional behaviour. ${ }^{8}$ The central issue is how to support and sustain that. To base a reform upon the opposite assumption therefore seems perverse. In assuming a narrow materialism we may risk creating the monster we fear. It seems an unhappy and even a dangerous export.

\footnotetext{
B Doriye (1992) makes this point in an article on the Tanzanian public services, arguing that privatization is not an appropriate response to corruption.
}

\section{REFERENCES}

Auerbach, P., 1988, Competition: The Economics of Industrial Change, Basil Blackwell, Oxford

Brooks, T. and Lowe, E., n.d., Quality in Contracts, Kings Funds Centre and National Association of Health Authorities

Buchanan, J., 1986, Liberty, Market and State, Wheatsheaf, Brighton

Chambers, D., 1989, Contribution to discussion in 'Building the contract relationship' Conference Papers 1 , Office of Public Management

Crow, B. and Harriss, B., 1992, 'Twentieth century free trade reform: food market deregulation in sub-Saharan Africa and South Asia', in Wuyts et al

Doriye, J., 1992, 'Public office and private gain: an interpretation of the Tanzanian experience', in Wuyts et al

East Anglian Regional Health Authority, 1990, Contracting for Health Outcomes, Office of Public Management, April

Enthoven, A., 1991, 'Internal market reform of the British National Health Service', Health Affairs, Autumn
Fergusson, B. and Posnett, J., 1990, 'Pricing and openness in contracts for health services', NHS White Paper Occasional Paper 11, Centre for Health Economics, University of York, January

Ham, C. and Matthews, T., 1991, 'Purchasing with authority', Kings Fund College Papers 1

Hawker, C. and Ritchie, R., n.d., 'Contracting for Community Care: Strategies for progress', Kings Fund Project Papers No 54

HMSO, 1989, Working for Patients

-1990, Contracts for Health Services: Operating Contracts, February

Hodgson, G., 1988, Economics and Institutions, Polity Press

Le Grand, J., 1991, 'Quasi-markets and social policy', Economic fournal No 101

Mackintosh, M., 1992, 'Questioning the state', in Wuyts et al

NHS Management Executive, 1991, 'Moving forward: needs, services and contracts', DHA Project Paper, March 
Sen, A. K., 1976, 'Rational fools: a critique of the behavioural foundations of economic theory', Philosophy and Public Affairs No 6; reprinted in F. Hahn and M. Hollis (eds.), Philosophy and Economic Theory, Oxford University Press, 1979

Strong, P. and Robinson, J., 1990, The NHS - Under New Management, Open University Press, Milton Keynes
Taylor, D., 1991, 'Developing primary care: opportunities for the 1990s', Research Report 10, Kings Fund Institute and Nuffield Provincial Hospitals Trust

Wuyts, M., Mackintosh, M. and Hewitt, T. (eds.), 1992, Development Policy and Public Action, Oxford University Press for the Open University 